\title{
Vertical Profiles and Chemical Properties of Aerosol Particles upon Ny-Ålesund (Svalbard Islands)
}

\author{
B. Moroni, ${ }^{1}$ S. Becagli, ${ }^{2}$ E. Bolzacchini, ${ }^{3}$ M. Busetto, ${ }^{4}$ D. Cappelletti, ${ }^{1,4,5}$ S. Crocchianti, ${ }^{5}$ \\ L. Ferrero, ${ }^{3}$ D. Frosini, ${ }^{2}$ C. Lanconelli, ${ }^{4}$ A. Lupi, ${ }^{4}$ M. Maturilli, ${ }^{6}$ M. Mazzola, ${ }^{4}$ \\ M. G. Perrone, ${ }^{3}$ G. Sangiorgi, ${ }^{3}$ R. Traversi, ${ }^{2}$ R. Udisti, $^{2}$ A. Viola, ${ }^{7}$ and V. Vitale ${ }^{4}$ \\ ${ }^{1}$ SMAArt Research Center, University of Perugia, 06125 Perugia, Italy \\ ${ }^{2}$ Department of Chemistry, University of Florence, 50019 Sesto Fiorentino, Italy \\ ${ }^{3}$ POLARIS Research Center, DISAT, University of Milano-Bicocca, 20126 Milano, Italy \\ ${ }^{4}$ Institute for Atmospheric Sciences and Climate, CNR, 40129 Bologna, Italy \\ ${ }^{5}$ Department of Chemistry, Biology and Biotechnologies, University of Perugia, 06123 Perugia, Italy \\ ${ }^{6}$ Alfred Wegener Institute, Helmholtz Centre for Polar and Marine Research, 14473 Potsdam, Germany \\ ${ }^{7}$ Institute for Atmospheric Sciences and Climate, CNR, 00133 Rome, Italy
}

Correspondence should be addressed to B. Moroni; b.moroni@tiscali.it

Received 25 December 2014; Revised 23 April 2015; Accepted 14 June 2015

Academic Editor: Richard Leaitch

Copyright (C) 2015 B. Moroni et al. This is an open access article distributed under the Creative Commons Attribution License, which permits unrestricted use, distribution, and reproduction in any medium, provided the original work is properly cited.

\begin{abstract}
Size-segregated particle samples were collected in the Arctic (Ny-Ålesund, Svalbard) in April 2011 both at ground level and in the free atmosphere exploiting a tethered balloon equipped also with an optical particle counter (OPC) and meteorological sensors. Individual particle properties were investigated by scanning electron microscopy coupled with energy dispersive microanalysis (SEM-EDS). Results of the SEM-EDS were integrated with particle size and optical measurements of the aerosols properties at ground level and along the vertical profiles. Detailed analysis of two case studies reveals significant differences in composition despite the similar structure (layering) and the comparable texture (grain size distribution) of particles in the air column. Differences in the mineral chemistry of samples point at both local (plutonic/metamorphic complexes in Svalbard) and remote (basic/ultrabasic magmatic complexes in Greenland and/or Iceland) geological source regions for dust. Differences in the particle size and shape are put into relationship with the mechanism of particle formation, that is, primary (well sorted, small) or secondary (idiomorphic, fine to coarse grained) origin for chloride and sulfate crystals and transport/settling for soil (silicate, carbonate and metal oxide) particles. The influence of size, shape, and mixing state of particles on ice nucleation and radiative properties is also discussed.
\end{abstract}

\section{Introduction}

The Arctic is the world region mostly affected by climate change $[1,2]$. Herein, climate forcing is causing dramatic environmental changes in a complex cycle of feedback processes involving atmosphere, ocean, cryosphere, and land [3]. In particular, the Arctic is undergoing large changes in extension and thickness of the annual and permanent sea ice and in the permafrost superficial structure (e.g., [4]). Changes in temperature profiles along the uppermost seawater layers and in the tropospheric air column involve relevant variations of the marine and atmospheric circulation processes, which are able on turn to significantly amplify the climate forcing on a hemispheric scale [5]. The increase in the Arctic cloud cover observed in the last decades may have significant effects too $[6,7]$. These observations raised public interest on global warming, which is actually more evident in the Arctic [8].

Arctic aerosol is believed to play a relevant role in climate-environment feedbacks by scattering and absorbing the solar radiation and by altering cloud properties $[9,10]$. Many of these effects remain poorly known, their quantitative evaluation is still limited [2], and this is one of the challenges of present aerosol research. For example, black carbon particles act as positive forcing agents because they 
enhance light absorption processes, while sulfate aerosols exert a negative forcing due to their prevalent scattering of the incoming solar radiation. Such effects are even more complex in polar regions, where snow and ice covered surfaces can have a higher surface albedo than aerosol layers or clouds. The role of natural aerosols (e.g., soil, marine spray) is also very important and dependent on properties such as hygroscopicity and particle shape. For example, sea salts have a significant influence on light scattering [11] while the structure and the composition of mineral dust have been found to exert a main action on cloud formation through homogeneous and heterogeneous ice nucleation processes [12].

An important consideration for both the radiation budget and cloud properties is the vertical distribution of aerosol particles in the troposphere. Studies on the planetary boundary layer (PBL) and the lower troposphere in the Arctic by lidar, radiometric and meteorological measurements revealed typical multilayered structures $[13,14]$ influenced also by particle transport and nucleation events [15]. In the light of all these points the study of the nature, properties, vertical distribution, and sources of aerosol particles in the lower troposphere provides a significant contribution to the understanding of key processes active in the Arctic climatic system.

Based on above remarks, in spring 2011, an intensive field campaign was carried out at the Italian station Dirigibile Italia in $\mathrm{Ny}$-Ålesund $\left(79^{\circ} \mathrm{N}\right.$, Svalbard $)$ in the framework of the "ARCTICA" PRIN (Progetto di Ricerca di Interesse Nazionale) project. The campaign was focused on study of chemical and physical properties of aerosols over there and long-range transport processes [16]. Vertical profiles of aerosol properties and ozone mixing ratio were carried out together with in situ ground level measurements.

In this paper results of individual particle characterization by scanning electron microscopy coupled with energy dispersive microanalysis (SEM-EDS) are reported and discussed. These results are integrated with particle size and optical (scattering, absorption) measurements of the aerosols at ground level and with optical particle counter (OPC) measurements along the vertical profiles, in order to improve our knowledge of the structure and processes in the lower Arctic Boundary Layer.

\section{Materials and Methods}

2.1. The Field Campaign. The field campaign was carried out at the Gruvebadet site, $\mathrm{Ny}$-Ålesund, between March 20 and May 5, 2011. Due to weather conditions, valid measurements were collected from April 5 to April 30. A total of 84 vertical profiles of variable height have been carried out up to $1 \mathrm{~km}$ using a tethered balloon equipped with a gondola developed for this field campaign. During each profile particle size distribution $(0.5-20 \mu \mathrm{m})$, black carbon concentration, meteorological parameters, and ozone mixing ratio have been recorded at $10-30 \mathrm{~m}$ resolution. In selected days, characterized by very stable conditions and low wind along the PBL, particle samples were collected leaving the

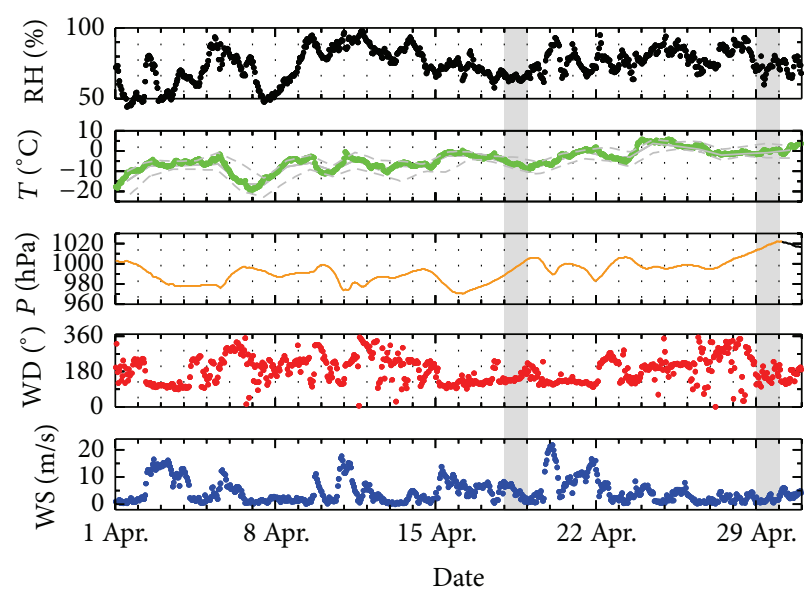

FIgure 1: Synopsis of April 2011. Data collected at the AmundsenNobile Climate Change Tower (CCT; http://www.isac.cnr.it/ radiclim/CCTower/) in Ny-Ålesund. For the temperature, high (upper dot line), mean (solid line), and low (lower dot line) values from the AWI meteorological tower (AWI, in grey) are also reported for comparison. Gruvebadet is located between CCT and AWI. Measurements from the two stations are in good accordance. The grey areas in the figure mark April 18 and April 29.

tethered balloon at a fixed height for periods of 3 to 6 hours. In such a way about 10 samples have been collected.

The synoptic conditions at Ny-Ålesund in April 2011 were characterized by low pressure in the first half of the month followed by a high pressure system. April 18 marked the transition of weather conditions. Before April 18 the mean values of the geopotential height at 850 and 500 mbar in the Ny-Ålesund area were 1208 and 5119 m; they turned to 1346 and $5311 \mathrm{~m}$ after that date (ECMWF).

Accordingly at ground (Figure 1), wind speeds were variable while surface air temperature and temperatures tended to increase sensibly after April 18. Specifically the average pressure increased from $986.3 \mathrm{hPa}$ before April 18 to $1002 \mathrm{hPa}$ after that date, and the pressure from 988.1 to $1005 \mathrm{hPa}$ during April 18. Samples representative of markedly different synoptic conditions have been collected on April 18 and on April 29. The back-trajectory analyses (see Section 2.2 below) suggest that the air masses sampled in these two different conditions originated from distinct source regions.

2.2. Case Studies Description. On April 18 the pressure level rapidly increased while the temperature reached a mean value of about $-7.4^{\circ} \mathrm{C}$. The wind speed at $10 \mathrm{~m}$ above ground was quite low $(<4 \mathrm{~m} / \mathrm{s})$ from ESE direction. Sporadic cloud events were also registered between 3000 and $6000 \mathrm{~m}$ altitude. April 29 was a typical synoptic high pressure situation. During the day, ground pressure was rising and surface air temperature was constantly below or around the freezing point (Figure 1). The wind speed at $10 \mathrm{~m}$ above ground was very low $(<3 \mathrm{~m} / \mathrm{s})$ from SE direction. This situation is typical for the orographically channelled wind during this time of the year [17]. The day was further characterized by a persistent cloud deck at $\sim 1 \mathrm{~km}$ altitude. These low-level clouds are quite common 


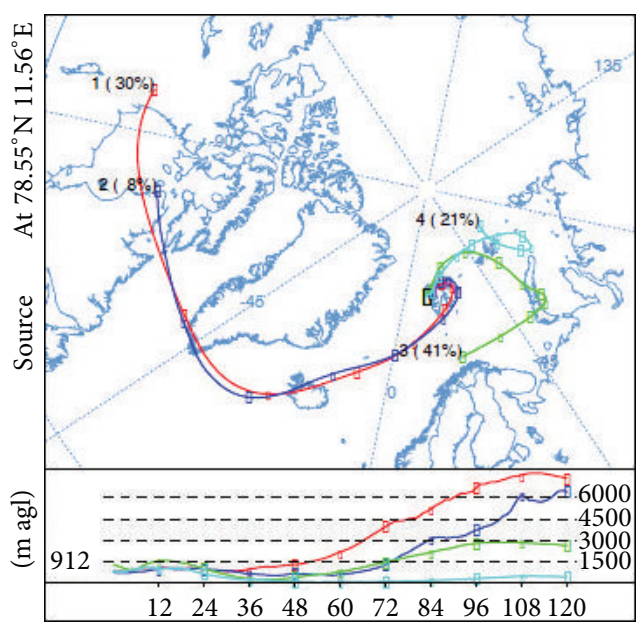

(a)

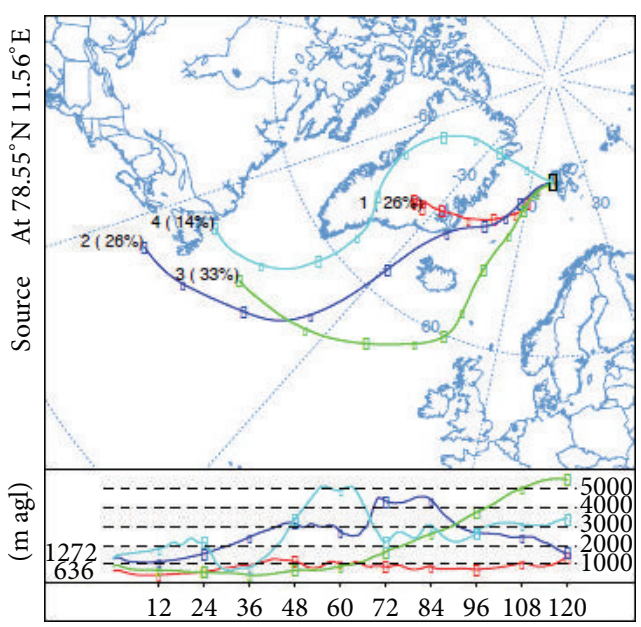

(b)

Figure 2: Clustered 5 d back-trajectories (BTs) for Apr 18 (a) and Apr 29 (b), 2011, calculated every 1 h using the NOAA HYSPLIT transport model [18]; meteorological data fields supplied by the ARL (Air Resources Lab, http://ready.arl.noaa.gov/gdasl.php) archiving programs input data. Endpoints are located above Ny-Ålesund at 500 m, 1000 m, and $1500 \mathrm{~m}$ agl.

in the springtime planetary boundary layer in Ny-Ålesund, related to local orography and persistent temperature inversion in the lower part of the atmosphere. The vertical profile of the radiosonde launched at 11 UTC on April 29 (not shown) revealed the orographical detachment of the wind regime below $1 \mathrm{~km}$ as well as the presence of several temperature inversions below $1 \mathrm{~km}$.

Air mass backward trajectories (cluster means) on April 18 and April 29 are shown in Figure 2. Four distinct clusters of trajectories are evident in both cases. On April 18 two clusters (accounting for 62\%) originate from Northern Russia, while a second pair of clusters originates from North America. In all cases the air masses experience a regular descending motion approaching Svalbard Islands. At earlier time (4-5 days before reaching Svalbard) the air masses from Northern Russia flew at lower altitudes (less than $3000 \mathrm{~m}$ agl) with respect to the air masses coming from North America. Lately (about two days before reaching Svalbard) all the clusters converged below $1500 \mathrm{~m}$ agl. On April 29 all the clusters come from Greenland and/or from the Northern Atlantic. For 18 April we have cyclonic movement, whereas on 29 April, the trajectory has an anticyclonic movement.

2.3. Ground Level Measurements. The Gruvebadet laboratory at the Dirigibile Italia Base in Ny-Ålesund is equipped with a series of instruments aimed at measuring physical and optical properties of aerosol at ground level. In particular size distribution measurements are carried out by an Aerodynamic Particle Sizer (TSI-APS 3321, 52 classes in the size range 0.5$20 \mu \mathrm{m}$ ) and by a Scanning Mobility Particle Sizer (TSI-SMPS 3034,54 classes in the size range $6-500 \mathrm{~nm}$ ). The two systems register one size spectrum every 10 minutes.

The scattering coefficient (Bsca) at $530 \mathrm{~nm}$ is measured by a Radiance Research M903 nephelometer at 1 s time resolution and stored as minute average. The absorption coefficient (Babs) is measured using a Radiance Research Particle Soot

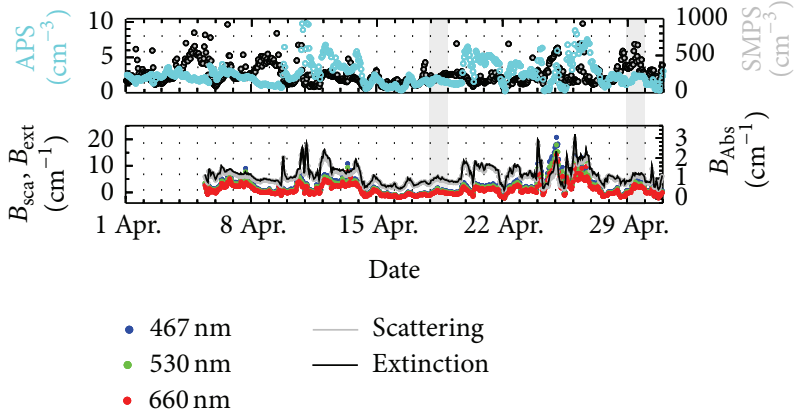

FIGURE 3: Integrated particle number concentration over the size range measured $\left(\mathrm{cm}^{-3}\right)$ and optical properties (scattering, extinction, and absorption coefficient at different wavelength; $\mathrm{cm}^{-1}$ ) at ground level (Gruvebadet station) in April 2011. The grey areas in the figure mark April 18 and April 29.

Absorption Photometer (PSAP) at three wavelengths (467, 530 , and $600 \mathrm{~nm}$ ), with the same temporal resolution.

Aerosol properties at the ground level during Apr 2011 are shown in Figure 3. In particular, on April 29, the numbers of particles with diameters $<500 \mathrm{~nm}$ were about $90 \%$ higher than those sampled on April 18, and particles $>500 \mathrm{~nm}$ were about $20 \%$ higher on April 29 compared with April 18. As a consequence, both the absorption and the scattering coefficients increased $(+69 \%$ and $+21 \%$, resp.). Change of single scattering albedo values from 0.93 on April 18 to 0.90 on April 29 confirms an overall increase of the absorbing fraction.

2.4. Vertical Profile Measurements. Vertical profile measurements have been carried out by means of a helium-filled tethered balloon (VAISALA; volume $\sim 7 \mathrm{~m}^{3}$; payload $\sim 5 \mathrm{~kg}$ ) equipped with (i) an optical particle counter (OPC, 1.107 Environcheck Grimm, 31 class-sizes ranging from 0.25 to 
TABLE 1: Meteorological conditions (temperature: $T$, relative humidity: RH, wind speed: WS, and wind direction: WD), time, duration, and height of sampling at ground and the balloon level.

\begin{tabular}{lcccccccc}
\hline Data & $T\left({ }^{\circ} \mathrm{C}\right)$ & $\mathrm{RH}(\%)$ & WS $(\mathrm{m} / \mathrm{s})$ & WD & Profiles (UTC) & Ground (UTC) & Balloon (UTC) & Height (m asl) \\
\hline $18 \mathrm{Apr}$ & -9 & 52 & 5 & NW & $17.25-17.35$ & $15.20(4 \mathrm{~h})$ & $16.45(3 \mathrm{~h})$ & $250 \mathrm{~m}$ \\
$29 \mathrm{Apr}$ & -1.2 & 99 & 1.6 & SE & $15.48-15.57$ & $15.50(4 \mathrm{~h})$ & $16.45(3 \mathrm{~h})$ & $260 \mathrm{~m}$ \\
\hline
\end{tabular}

$32 \mu \mathrm{m}$ calibrated by the manufacturer just before the campaign) for particle number-size distribution determination; (ii) a miniaturized cascade impactor (Sioutas SKC with 2 impaction stages and $0.65 \mu \mathrm{m}$ cut-off) for particulate matter collection on sampling filters (polycarbonate, $25 \mathrm{~mm}$ ); (iii) a meteorological station (Vaisala Tethersonde TTS 111). The balloon ascent/descent rate was controlled by an electric winch (Vaisala Electric Winch TTW111). The maximum height of flights depended on atmospheric conditions (wind speed); in most cases it was between 600 and $800 \mathrm{magl}$. Depending on the weather conditions and on the type of experiment the payload included also a miniaturized electrical nanoparticle detector (DiSCmini, Matter Aerosol) and a microaethalometer (Magee AE-51), but those data will be discussed elsewhere. The sampling periods with corresponding environmental conditions are reported in Table 1.

2.5. SEM-EDS Microanalyses. For individual particle characterization, single portions $(\sim 10 \times 10 \mathrm{~mm})$ were cut from the central part of the sampling filters and mounted on to SEM aluminium stubs using double-sided carbon tape. Samples were then coated with a $100-150 \AA$ carbon film to provide electrical conductivity and to prevent charge build-up during the exposure to the electron beam.

Conventional SEM-EDS microanalyses were performed at the Centro Universitario di Microscopia Elettronica (CUME), University of Perugia (Italy), using a Philips XL30 instrument equipped with an X-ray energy dispersive spectrometer (EDS-EDAX DX-4I, coupled with GENESIS software for data treatment). The instrument was operated at $20 \mathrm{kV}$ acceleration voltage and variable magnification $(2,000$ to $20,000 x)$ depending on particle size. EDS spectra (spot size 5, working distance $10 \mathrm{~mm}$ ) were collected for $30 \mathrm{~s}$ live time and the $\mathrm{X}$-ray count rates were corrected for matrix effects using the so-called "standardless" procedures provided by the GENESIS software. The analysis started in the middle of the sample, the scan probe was moved on a chosen direction, and the particles were analyzed manually one by one at the proper magnification. Using this procedure approximately 100 particles per filter were analysed. Indeed, this is a small number of particles in itself, but it was obtained on very large portions of the filters $\left(\sim 0.5 \mathrm{~mm}^{2}\right)$ as the number density of particles on the filters was generally very low. On the other hand, individual particle analysis performed on a nonautomated instrument on disperse samples, like in this case, is very time consuming. We, thus, believe that the number of particles analysed per sample is an acceptable compromise to obtain representative results at reasonable analytical time.

The samples collected on 29 April 2011, which were particularly enriched in particles, underwent detailed individual particle characterization by computer controlled SEM analysis (CCSEM). In this procedure, software scans fields one at a time in automated mode, detecting the single particles and recording morphology (digitalized image) and chemical composition (spectrum) data on a large number of particles. Measurements were performed at the Department of Physics, University of Fribourg (Switzerland), using a FEI XL 30 Sirion FEG environmental scanning electron microscope equipped with an EDAX Pegasus EDS system. The system was operated at $25 \mathrm{kV}$ acceleration voltage and fixed magnification $(2000 \mathrm{x})$. Analyses were performed on selected representative fields of the filter after evaluation of sample uniformity, adequate greyscale calibration, and proper definition of the working parameters. EDS spectra of more than 2000 particles were collected for $15 \mathrm{~s}$ live time and the chemical composition (elements with $Z \geq 5$ ) obtained using the standardless procedures provided by the EDAX software.

All EDS spectra were manually reviewed and particles whose signal was too weak were discarded. Element concentrations lower than 0.1 weight \% (SEM detection limit) were omitted. According to Kandler et al. [19] approach, the elemental atomic ratios were calculated and then compared with those of pure minerals and phases to obtain distinct particle classes.

Digitalized images underwent image analysis (IA). In the conventional procedure the manually selected particles were analysed using the software Image Tool 3.0 (http://compdent.uthscsa.edu/dig/). In the CCSEM procedure the particle analysis software allows automatic recognition of the particles based on the contrast on back scatter (BSE) images. A BSE image as well as morphological parameters (different diameters) and the chemical composition is determined for each particle and stored. A set of morphological parameters for each particle grain was obtained. In this paper Feret diameter (FD) and shape factor (SF) are considered. According to Russ [20], Feret diameter is the diameter of a circle having the same area as the object:

$$
\mathrm{FD}=\sqrt{\frac{4 A}{\pi}}
$$

The shape factor is defined as the reciprocal of roundness:

$$
\mathrm{SF}=\frac{P^{2}}{4 \pi A}
$$

$A$ and $P$ are the area and the perimeter of the geometrical projection of a particle within the image. Feret diameter and shape factor, thus, provide a measurement of the mean grain size and the border complexity of grains, respectively. The analytical precision, obtained from triplicate measurements of selected particles at different magnification $(5000 \mathrm{x}, 10000 \mathrm{x}$, 


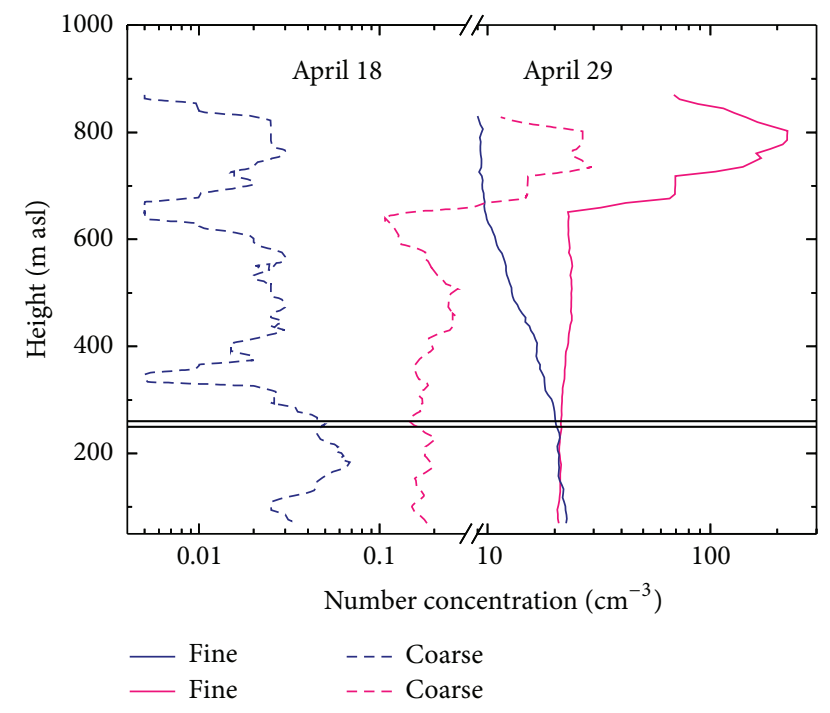

(a)

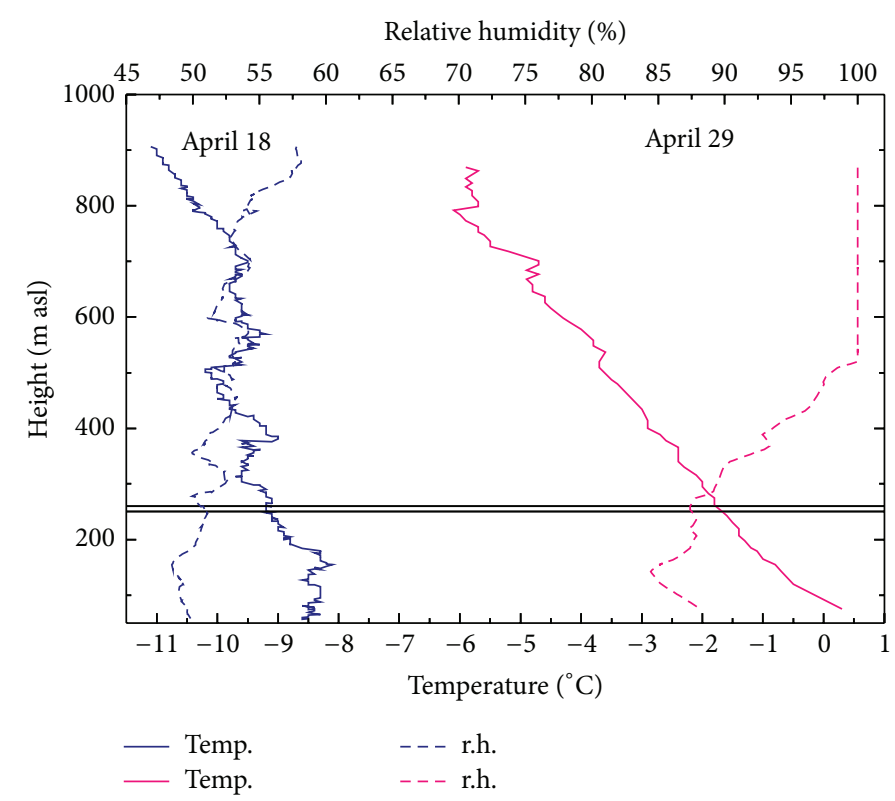

(b)

FIGURE 4: (a) Vertical profiles of particle number concentration of fine (solid lines) and coarse particles (dashed lines) on April 18 (blue lines) and April 29, 2011 (red lines); (b) temperature (solid lines) and relative humidity profiles (dashed lines) during the measurements. The black lines mark the height of sampling at the balloon level on both days. Data were obtained from measurements performed just before the sample collection for SEM microanalyses.

and $20000 x$ ), is better than $2 \%$ for Feret diameter and better than $5 \%$ for the shape factor.

\section{Results and Discussion}

3.1. Aerosol Structures. Examples of aerosol vertical profiles recorded on the 18 and 29 of April are reported in Figure 4 (see also Table 1). Particle number concentration measurements along the vertical profiles reveal a marked stratification on Apr 18, not present on Apr 29 (Figure 4), correlated with the presence of temperature inversions (Figures 4(a) and 4(b)). In particular, fine particles show a gradual decrease of concentration as altitude increases from $\sim 250$ to $\sim 650 \mathrm{~m}$ asl; coarse particles, on turn, show a sudden and reversal trend in the same height span. The abrupt increase of both fine and coarse particles at $\sim 600 \mathrm{~m}$ agl on April 29 is related to the presence of clouds, that is, water droplet particles. Cloud height measurements by ceilometer on the same day gave comparable results (see Section 2).

When looking to the particle size distributions (Figure 5) we note that patterns for fine particles are quite similar in both days (Figures 5(c) and 5(d)) while patterns for coarse particles are very distinguishable (Figures 5(a) and 5(b)). In particular, number concentrations on April 29 are one order of magnitude higher than those on April 18. Backward trajectory analyses reveal very different source areas for the air masses on those days (Figure 2). This analysis suggests a major influence of long-range transport from North Atlantic and Greenland sectors on April 29 and from Northern Russia on April 18. It has to be noted, however, that the recorded particle size distributions are almost homogeneous with height (excluding the cloud event of 29th). This means that stratification mostly involves number rather than size distribution of particles.

3.2. Particle Types. Five main particle types were observed in the samples, namely, silicates, carbonates, sulfates, chlorides, and metal oxides. Soot particles have been also evidenced in a few cases. Except for soot and $\mathrm{Cu}$-oxides, which are both from vehicular/combustive sources, the rest of particles are from natural (soil) sources. Particles in most cases consist of internally or externally mixed solid phases. The pie plots in Figure 6 report the relative abundance of solid particles in the aerosol at ground level and $260 \mathrm{~m}$ asl on April 18 and April 29, 2011.

A great change in composition is observed at different levels in the lower troposphere on both days. At ground level, the chlorides (mostly Na chloride) are the main constituent of natural aerosol, followed by the silicates. Metal oxide particles and alkaline sulfates form significant parts of dust on April 18 and 29, respectively, while a few carbonate oxide particles are present in both samples. The chlorides are generally well below $1 \mu \mathrm{m}$ and quite homogeneous in size, while the alkaline sulfates are above $1 \mu \mathrm{m}$ and show a regular shape (Figure 7(a)). The abundance, size, and shape of particles suggest a common origin from primary marine aerosol for both the chlorides and alkaline sulfates [21, 22]. The silicate minerals, on turn, consist of isolated crystals or, more frequently, they form clusters or aggregates. In this latter case the typical, roundish shape of the clusters indicates settling from water droplets (Figure 7(b)) during (or just after) sample collection. 


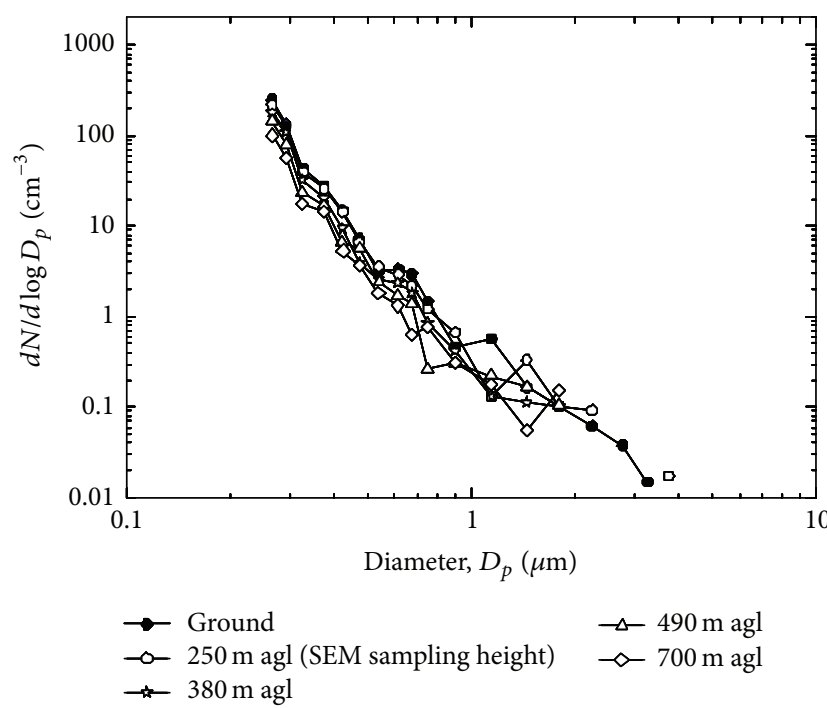

(a)

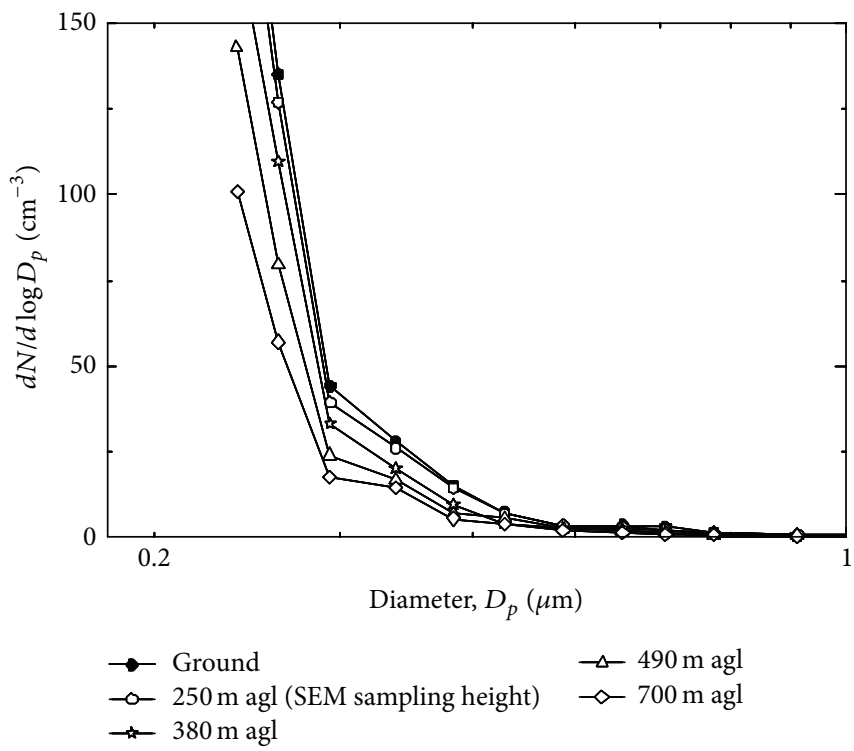

(c)

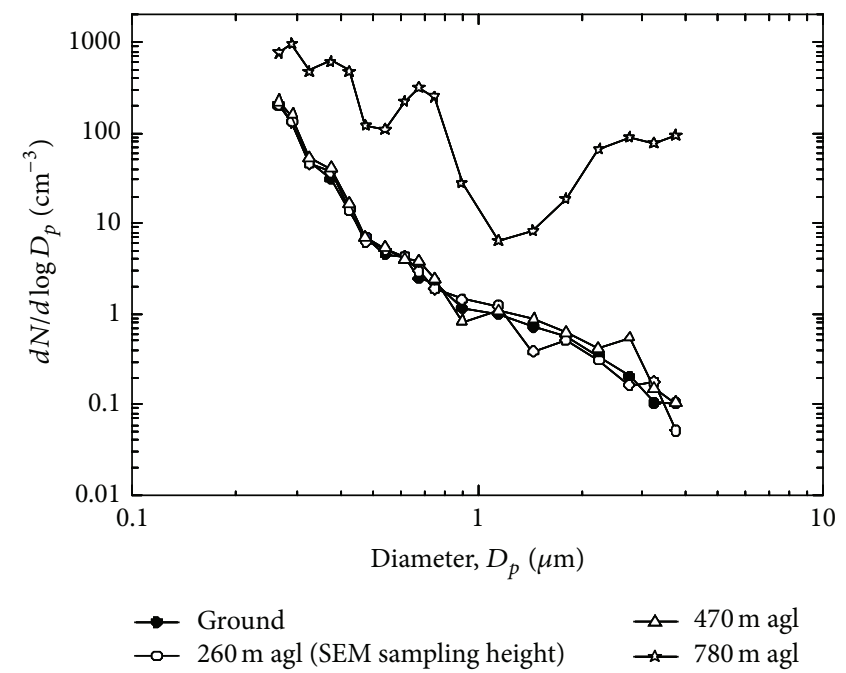

(b)

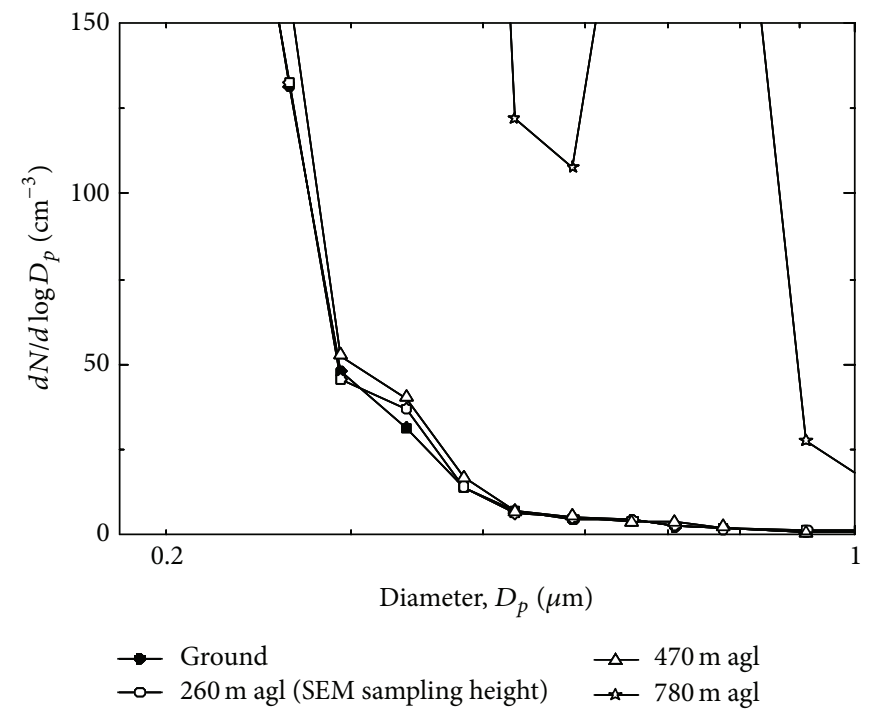

(d)

Figure 5: Aerosol particle size distribution at different height on April 18 (a, c) and April 29 (b, d), 2011. Data were obtained from measurements performed just before the sample collection for SEM microanalyses.

At $260 \mathrm{~m}$ asl the silicates, mostly in the form of quartz and/or clay sheet minerals, are the main constituent of airborne dust; at this height a remarkable part of gypsum along with significant amounts of metal oxides is also present on April 29 (Figure 6). All these minerals are fine (mean diameter $<2.5 \mu \mathrm{m}$ ) to coarse grained (mean diameter $>$ $2.5 \mu \mathrm{m}$ ); the shape is irregular to roundish in the silicates and the metal oxides and very regular in the gypsum crystals (Figure 8). The soil particles, namely, the silicates, carbonates, and metal oxides, are involved in transport and settling processes related to long/short range transport from natural sources, while gypsum is from heterogeneous nucleation processes. According to Sinha et al. [23], the typical (idiomorphic) shape of gypsum suggests a secondary origin from incloud processes involving airborne carbonate.
3.3. Particle Sources. In the samples collected on April 29, whose quantity was sufficiently high to obtain a significant number of particles for analysis, the mineral chemistry of the metal particles and the sheet silicates has been evaluated for source identification purposes.

Most metal particles in this sample are associated with $\mathrm{Fe}$-Cr spinel oxides; a significant part of Fe-oxides and/or hydroxides is also present, along with a small number of $\mathrm{Fe}$ - and/or Ti-oxides (Figure 9). The distinct metal particles can be associated with different geodynamic contexts; that is, the Fe-Ti-oxides (and hydroxides) are best found in plutonic/metamorphic complexes, whereas the spinel metal oxides are typically associated with basic/ultrabasic plutonic/volcanic rock terrains [24]. Both geological/geodynamic contexts can be sources for particles 
April 18

$(N=93)$

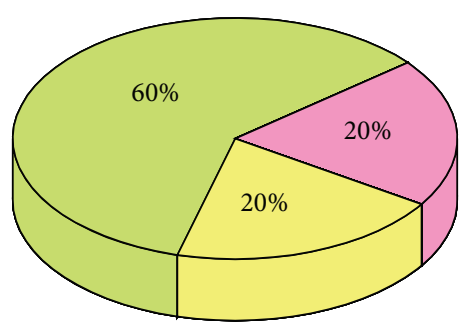

$(N=103)$

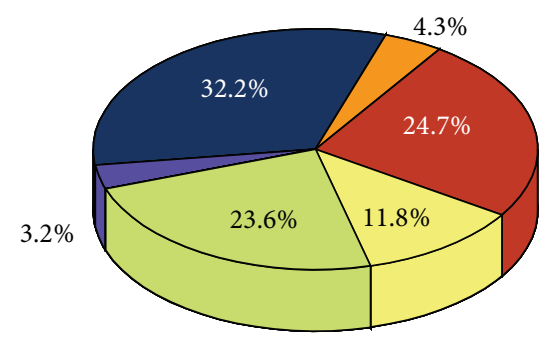

April 29
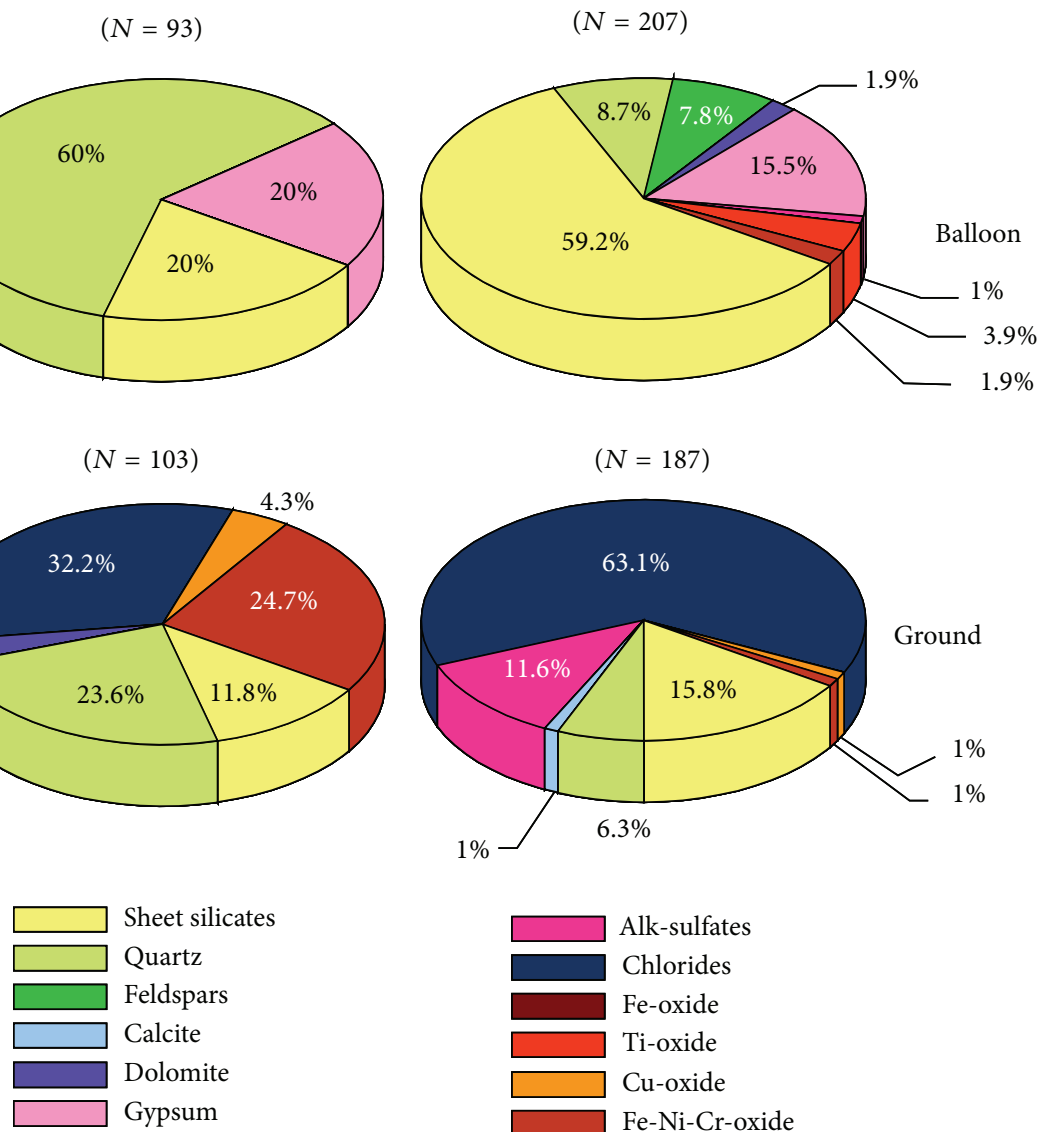

FIGURE 6: Relative abundance (\% number) of the particle types in the total suspended particulate matter at ground and balloon level on April 18 and April 29, 2011. The height of balloon sampling was $250 \mathrm{~m}$ asl on April 18 and $260 \mathrm{~m}$ on April 29. Carbonaceous particles have been subtracted from the calculations. The number of particles analyzed is reported in parenthesis.

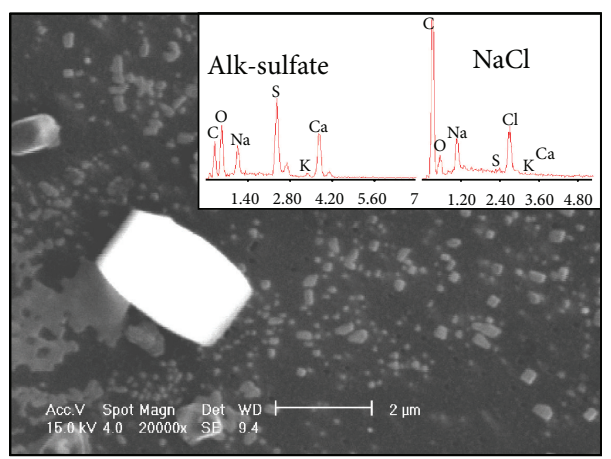

(a)

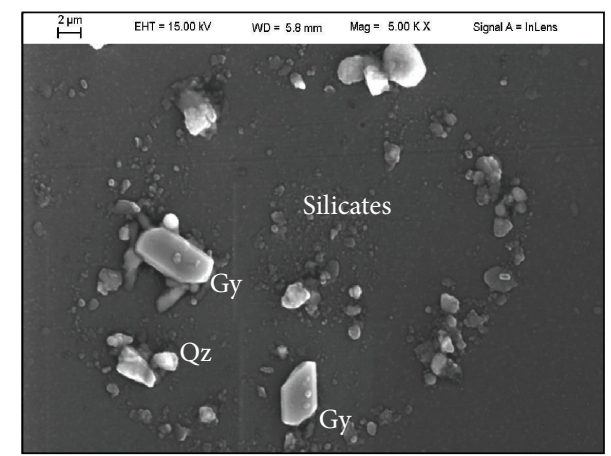

(b)

FIGURE 7: SEM micrographs illustrating the characteristics of the particle types at ground level: (a) sodium chloride and alkaline sulfates; (b) silicate and sulfate deposits. In (b) the roundish area containing the grains marks the original shape of a water droplet. Qz: quartz; Gy: gypsum; silicates: undefined.

at Svalbard Islands. Local basement rocks do, actually, outcrop in the surroundings of $\mathrm{Ny}$-Ålesund [25], while tholeiitic volcanic and plutonic rocks widely outcrop in Iceland [26] and East Greenland (e.g., Skaergaard intrusion [27]). Results of back-trajectory analysis for April 29 do, actually, support a dust provenance from both sites (Figure 2(b)), but the characteristics of Icelandic soils and airborne dusts analyses [26] for comparison do not resemble those of our dust samples. Therefore, provenance form Greenland is more reliable in this case. 


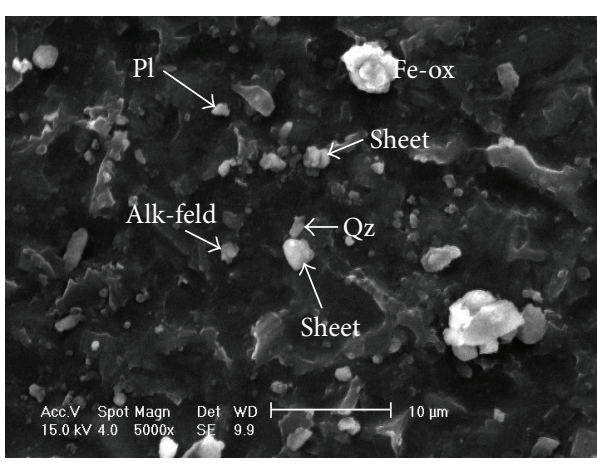

(a)

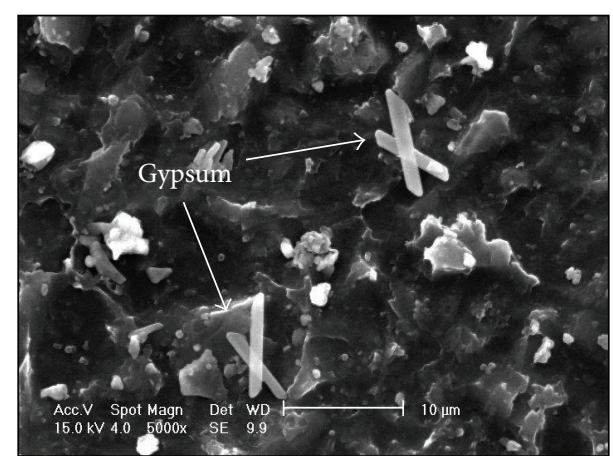

(b)

FIGURE 8: SEM micrographs illustrating the characteristics of the particle types at $260 \mathrm{~m}$ asl: (a) silicates and metal oxides (Pl: plagioclase; Alk-feld: alkali feldspar; Qz: quartz; sheet: undefined sheet clay mineral; Fe-ox: iron oxide); (b) gypsum crystals.

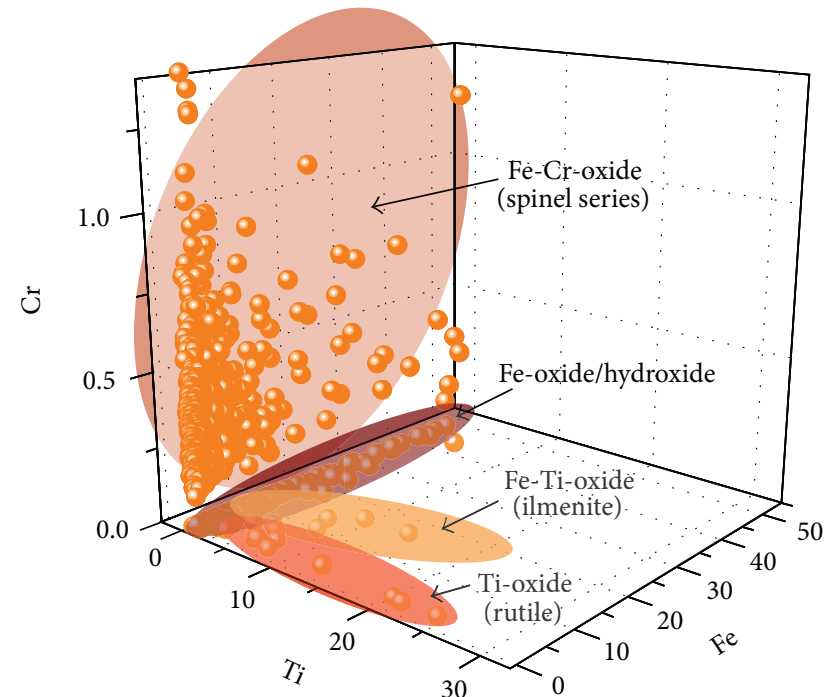

FIGURE 9: Chemical composition of the metal particles in the aerosol dust sampled at $260 \mathrm{~m}$ asl on April 29.

Sheet silicates sampled at ground level are slightly enriched in $\mathrm{Al}$ and $\mathrm{Fe}$, while those sampled at $260 \mathrm{~m}$ asl are enriched in $\mathrm{Mg}$ (Figure 10). This feature, which is a marker for different soil types and/or particle evolution by transport in the air masses, cannot be clearly associated with specific source areas for the lack of representative soil/dust samples for comparison. Results of mineral chemistry characterization are not sufficient in this case to decide on the provenance.

3.4. Particle Properties. Ice crystals in the atmosphere have important impacts on radiative transfer, precipitation formation, and the microphysical and optical properties of clouds. Ice is formed in clouds either by homogeneous freezing of water and solution droplets at temperatures below about $-35^{\circ} \mathrm{C}$ or by heterogeneous ice nucleation processes induced by insoluble aerosol particles [28]. We can expect these processes to be possibly relevant on April 29 for the high relative humidity conditions (Figure 4 ) and, above all, for the remarkably higher amounts of mineral dust particles found in the aerosol on that day.

The particle size distribution of the silicate minerals upon Ny-Ålesund shows two main modes in the submicron size range (Figure 11). Comparable freezing experiments show this mode diameter to prevent ice nucleation in the range of temperatures found both at ground and at the balloon level [28]. Supermicron clay mineral particles, on turn, are often coated by sulfate mantles (Figure 12(a)), and this feature is found to depress their ice nucleation efficiency [28].

The size, the morphology, and the composition of sea salt particles have been found to exert direct effects on the aerosol radiative impact [29]. In order to estimate the mode and the extent of action of these particles in the lower troposphere the shape factor of chloride and sulfate particles found at ground level and at $260 \mathrm{~m}$ asl on April 29 were measured and compared. Looking to the results (Figure 12), the salt particles at $260 \mathrm{~m}$ asl are much less spherical in shape than the particles taken at ground level. In fact, at $260 \mathrm{~m}$ asl a significant fraction ( 20\%) of salt particles have a shape factor higher than 2.0, while at ground level only a very few particles have similar values. Such different morphology depends on the intrinsic nature of particles. Sulfate and chloride particles at $260 \mathrm{~m}$ asl are, in many instances, internally mixed particles consisting of silicate minerals mantled by sulfate and chloride crusts (inset in Figure 12(a)), namely, the product of incloud aging processes of salt hygroscopic growth occurring upon particles transported by the air masses. Salt minerals at ground level, on turn, are mostly individual or externally mixed particles resulting from sea spray (Figure 12(b)). A distinct radiative impact of aerosol particles is, thus, to be expected at different height in the lower troposphere even for the same particle type due to the particle size and morphology.

\section{Conclusion}

In this study, some aspects of aerosol characterization upon Svalbard Islands have been discussed focusing on the properties of the constituent particle types at different height in 


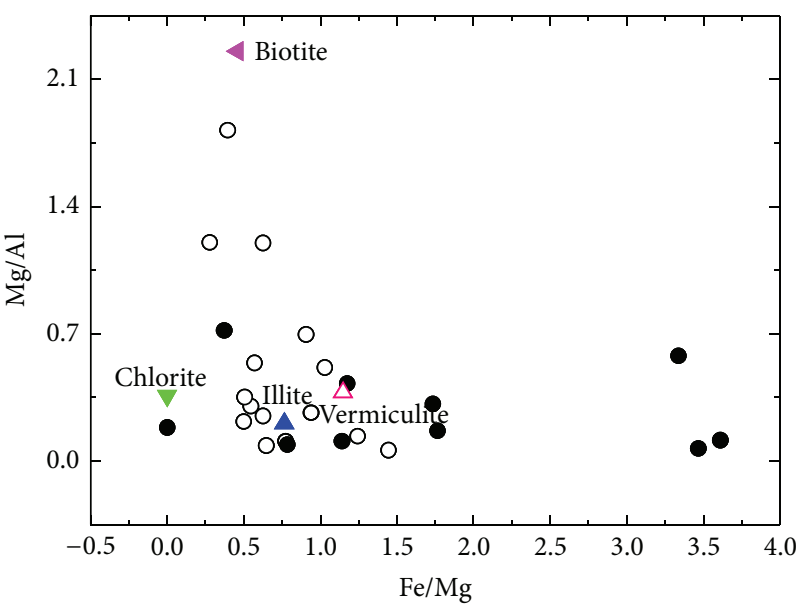

Ground ○ Balloon

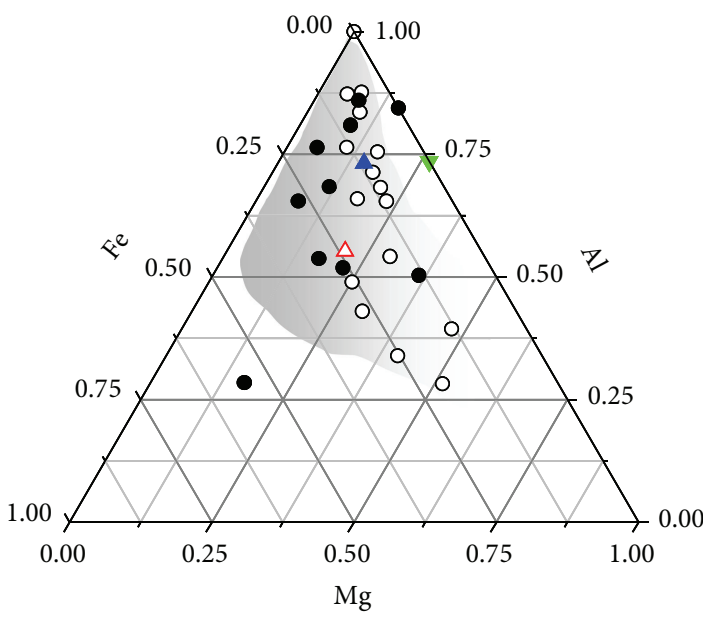

Ground

Balloon

Figure 10: Chemical composition of the sheet minerals in the aerosol dust sampled at $260 \mathrm{~m}$ asl.

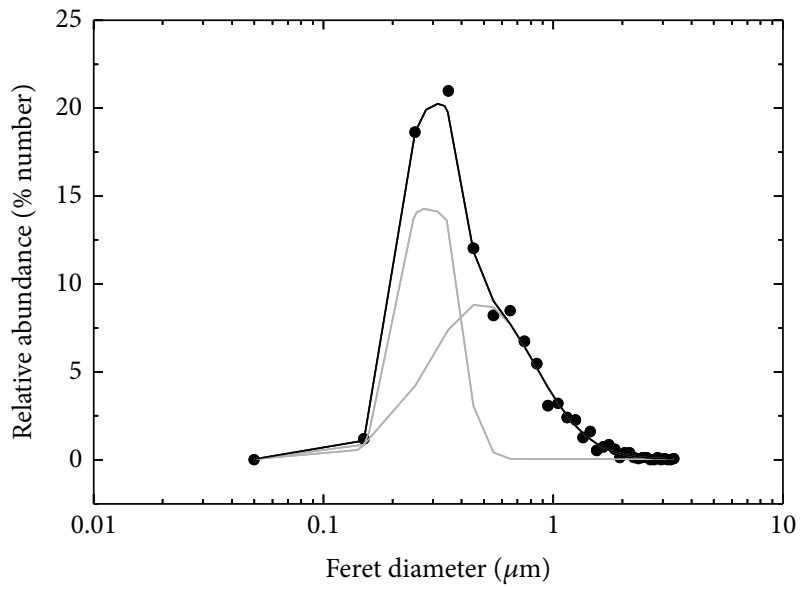

FIGURE 11: Frequency plot of Feret diameter in the silicate particles collected at $260 \mathrm{~m}$ asl upon $\mathrm{Ny}$-Ålesund on April 29. Data obtained by CCSEM individual particle image analysis.

the troposphere. Detailed analysis of selected samples representing typical synoptic conditions revealed significant differences in composition despite the similar structure (layering) and the comparable texture (size distribution) of the particles in the air column. These differences have been explained considering the combined action of transport (long, short range) and aging (settling by gravity, salt hygroscopic growth) on the particle properties.

The mineral chemistry of different particle types revealed interesting differences among the samples. In particular, in the case of the metal oxides, the specific geochemical features of different particle types led to distinguishing different geological sources for the particles. These features make metal oxides good markers of geographic provenance, provided a consistent geochemical databank of representative metal oxide particle populations from different geological sources/source regions is arranged. The question of provenance should be, thus, addressed following a more detailed analytical protocol as for the number of particles and, especially, the reference samples for comparison. Combined with bulk geochemical records and back-trajectory statistical evaluation, this approach could be exploited to evaluate the contribution of different source areas to the aerosol particles in the site.

Both the origin and the source regions of particles deeply mark their properties. Differences in the shape, size, and the state of mixing of the particles have been put into relationship with their origin and evolution within the air column over the site. In particular, the size of the silicates significantly affects their ability to act as cloud condensation and/or ice nucleation active sites, while the shape of sulfate minerals may influence the scattering and absorption properties of the aerosol at different level in the troposphere depending on the extent of aging processes (settling, layering). These latter are able, on turn, to influence the radiative budget in the troposphere through direct (light scattering and absorption) and indirect (cloud formation and evolution, cloud microphysical and optical properties) effects.

\section{Conflict of Interests}

The authors declare that there is no conflict of interests regarding the publication of this paper.

\section{Acknowledgments}

The authors thank Bernard Grobety and Christophe Neururer, University of Fribourg, for valuable support and precious help in the CCSEM analyses. This study was funded by the Italian Ministry of University and Research (PRIN2009 project). The logistic assistance of the Polar Support 


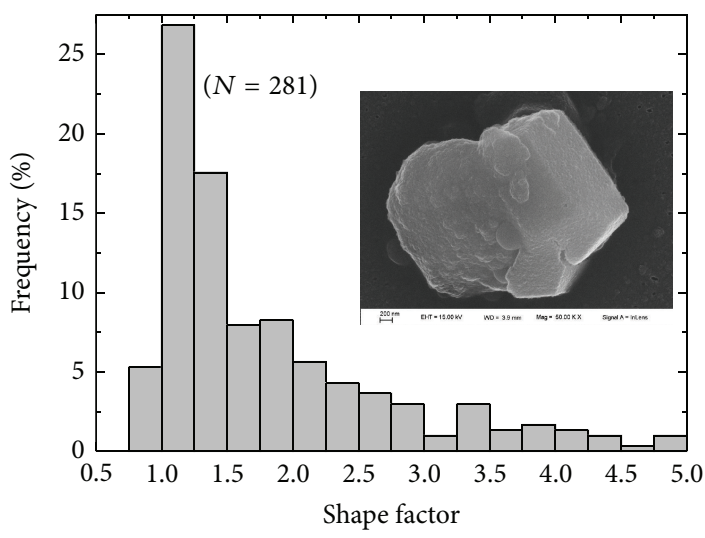

Sulfate + chloride

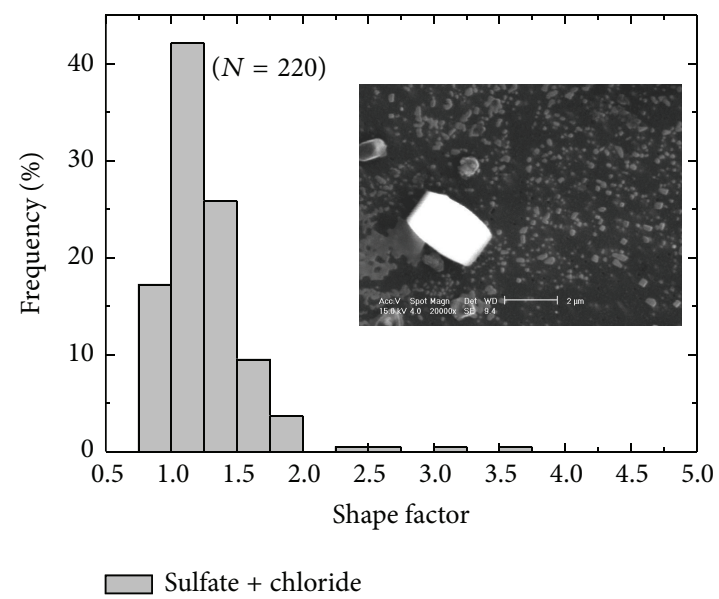

(b)

FiguRE 12: Frequency plots of the shape factor, SF, of sulfate and chloride particles: (a) at $260 \mathrm{~m}$ asl; (b) at ground level. $N$ is the number of particles analyzed in each sample. The inset micrographs illustrate the typical particle features.

Unit of the CNR Department of Earth and Environment (POLARNET) is gratefully acknowledged.

\section{References}

[1] R. Corell, Arctic Climate Impact Assessment, Cambridge University Press, Cambridge, UK, 2004.

[2] IPCC, "Climate change 2013: the physical science basis. Contribution of working group I to the fifth assessment report of the intergovernmental panel on climate change," in Climate Change 2013: The Physical Science Basis. Contribution of Working Group I to the Fifth Assessment Report of the Intergovernmental Panel on Climate Change, T. F. Stocker, D. Qin, G.-K. Plattner et al., Eds., p. 1535, Cambridge University Press, Cambridge, UK, 2013.

[3] J. A. Curry, W. B. Rossow, D. Randall, and J. L. Schramm, "Overview of arctic cloud and radiation characteristics," Journal of Climate, vol. 9, no. 8, pp. 1731-1764, 1996.

[4] S. V. Nghiem, I. G. Rigor, D. K. Perovich, P. Clemente-Colón, J. W. Weatherly, and G. Neumann, "Rapid reduction of Arctic perennial sea ice," Geophysical Research Letters, vol. 34, no. 19, Article ID L19504, 2007.

[5] Y. Cao and J. Zhao, "Progress of Chinese research in Arctic physical oceanography during 2007-2010," Advances in Polar Science, vol. 22, no. 4, pp. 281-292, 2011.

[6] J. E. Kay, T. L'Ecuyer, A. Gettelman, G. Stephens, and C. O'Dell, "The contribution of cloud and radiation anomalies to the 2007 Arctic sea ice extent minimum," Geophysical Research Letters, vol. 35, no. 8, Article ID L08503, 2008.

[7] S. Vavrus, "The impact of cloud feedbacks on arctic climate under greenhouse forcing," Journal of Climate, vol. 17, no. 3, pp. 603-615, 2004.

[8] A. Gore, An Inconvenient Truth: The Planetary Emergency of Global Warming and What We Can Do About It, Melcher Media, New York, NY, USA, 2006.

[9] C. Tomasi, A. Lupi, M. Mazzola et al., "An update on polar aerosol optical properties using POLAR-AOD and other measurements performed during the International Polar Year," Atmospheric Environment, vol. 52, pp. 29-47, 2012.
[10] U. Lohmann and J. Feichter, "Global indirect aerosol effects: a review," Atmospheric Chemistry and Physics, vol. 5, no. 3, pp. 715-737, 2005.

[11] C. A. Randles, L. M. Russell, and V. Ramaswamy, "Hygroscopic and optical properties of organic sea salt aerosol and consequences for climate forcing," Geophysical Research Letters, vol. 31, no. 16, Article ID L16108, 2004.

[12] L. Smoydzin, A. Teller, H. Tost, M. Fnais, and J. Lelieveld, "Impact of mineral dust on cloud formation in a Saharan outflow region," Atmospheric Chemistry and Physics Discussion, vol. 11, pp. 32363-32390, 2011.

[13] S. Argentini, A. P. Viola, G. Mastrantonio, A. Maurizi, T. Georgiadis, and M. Nardino, "Characteristics of the boundary layer at Ny-Ålesund in the Arctic during the ARTIST field experiment," Annals of Geophysics, vol. 46, no. 2, pp. 185-196, 2003.

[14] A. Dörnbrack, I. S. Stachlewska, C. Ritter, and R. Neuber, "Aerosol distribution around Svalbard during intense easterly winds," Atmospheric Chemistry and Physics, vol. 10, no. 4, pp. 1473-1490, 2010.

[15] J. Ström, J. Umegård, K. Tørseth et al., "One year of particle size distribution and aerosol chemical composition measurements at the Zeppelin Station, Svalbard," Physics and Chemistry of the Earth, vol. 28, pp. 1181-1190, 2003.

[16] R. Udisti, S. Becagli, D. Frosini et al., "Climate and environment. Activity and preliminary results from the 2011 and 2012 field seasons at Ny-Ålesund," in Research Activity in Ny-Ålesund 2011-2012, T. Ciciotti, P. Braico, E. Liberatori, L. M. Villanova, and R. Sparapani, Eds., pp. 53-68, National Research Council of Italy, CNR Edizioni, 2011.

[17] M. Maturilli, A. Herber, and G. König-Langlo, "Surface radiation climatology for $\mathrm{Ny}$-Ålesund, Svalbard $\left(78.9^{\circ} \mathrm{N}\right)$, basic observations for trend detection," Theoretical and Applied Climatology, vol. 120, no. 1-2, pp. 331-339, 2014.

[18] R. R. Draxler and G. D. Rolph, HYSPLIT (HYbrid Single-Particle Lagrangian Integrated Trajectory) Model, NOAA Air Resources Laboratory, Silver Spring, Md, USA, 2003.

[19] K. Kandler, N. Benker, U. Bundke et al., "Chemical composition and complex refractive index of Saharan mineral dust at Izaña, 
Tenerife (Spain) derived by electron microscopy," Atmospheric Environment, vol. 41, no. 37, pp. 8058-8074, 2007.

[20] J. C. Russ, The Image Processing Handbook, CRC Press, New York, NY, USA, 2nd edition, 1995.

[21] U. Behrenfeldt, R. Krejci, J. Ström, and A. Stohl, "Chemical properties of Arctic aerosol particles collected at the Zeppelin station during the aerosol transition period in May and June of 2004," Tellus, Series B: Chemical and Physical Meteorology, vol. 60, no. 3, pp. 405-415, 2008.

[22] S. Weinbruch, D. Wiesemann, M. Ebert, K. Schütze, R. Kallenborn, and J. Ström, "Chemical composition and sources of aerosol particles at Zeppelin Mountain (Ny ålesund, Svalbard): an electron microscopy study," Atmospheric Environment, vol. 49, pp. 142-150, 2012.

[23] B. W. Sinha, P. Hoppe, J. Huth, S. Foley, and M. O. Andreae, "Sulfur isotope analyses of individual aerosol particles in the urban aerosol at a central European site (Mainz, Germany)," Atmospheric Chemistry and Physics, vol. 8, no. 23, pp. 7217-7238, 2008.

[24] D. Rumble, "Oxide minerals," Mineralogical Society of America, Short Course Notes, vol. 3, p. 502, 1976.

[25] W. B. Harland, The Geology of Svalbard, vol. 17 of Memoir, Geological Society, London, UK, 1997.

[26] D. Baratoux, N. Mangold, O. Arnalds et al., "Volcanic sands of Iceland-Diverse origins of aeolian sand deposits revealed at Dyngjusandur and Lambahraun," Earth Surface Processes and Landforms, vol. 36, no. 13, pp. 1789-1808, 2011.

[27] C. K. Brooks, "The Skaergaard intrusion: from icon to precious metal deposit," Geology Today, vol. 21, no. 6, pp. 218-221, 2005.

[28] C. Hoose and O. Möhler, "Heterogeneous ice nucleation on atmospheric aerosols: a review of results from laboratory experiments," Atmospheric Chemistry and Physics, vol. 12, no. 20, pp. 9817-9854, 2012.

[29] I. N. Tang, "Chemical and size effects of hygroscopic aerosols on light scattering coefficients," Journal of Geophysical Research, vol. 101, no. 14, pp. 19245-19250, 1996. 

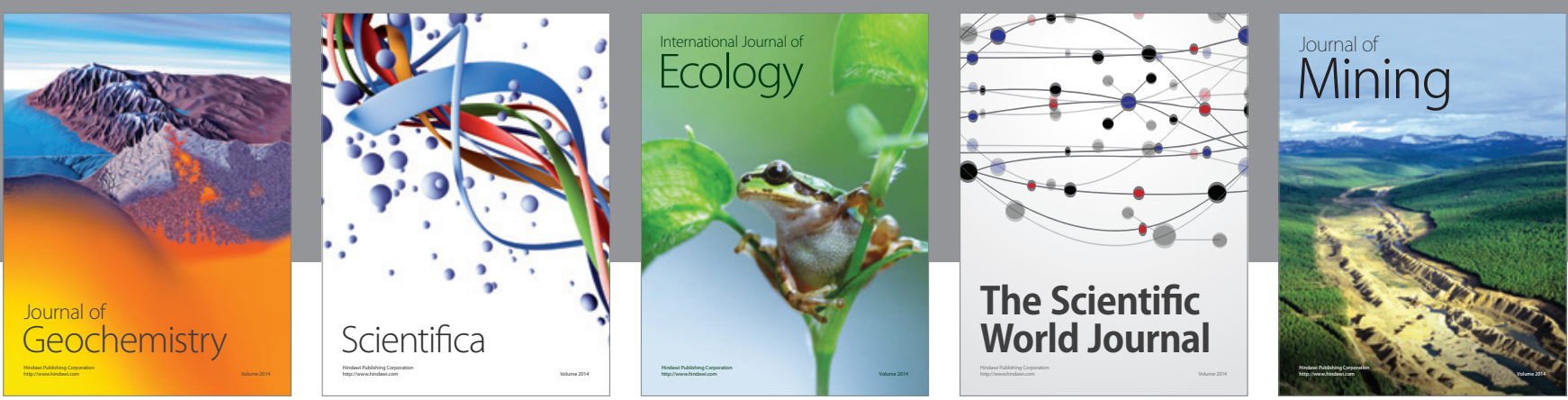

The Scientific World Journal
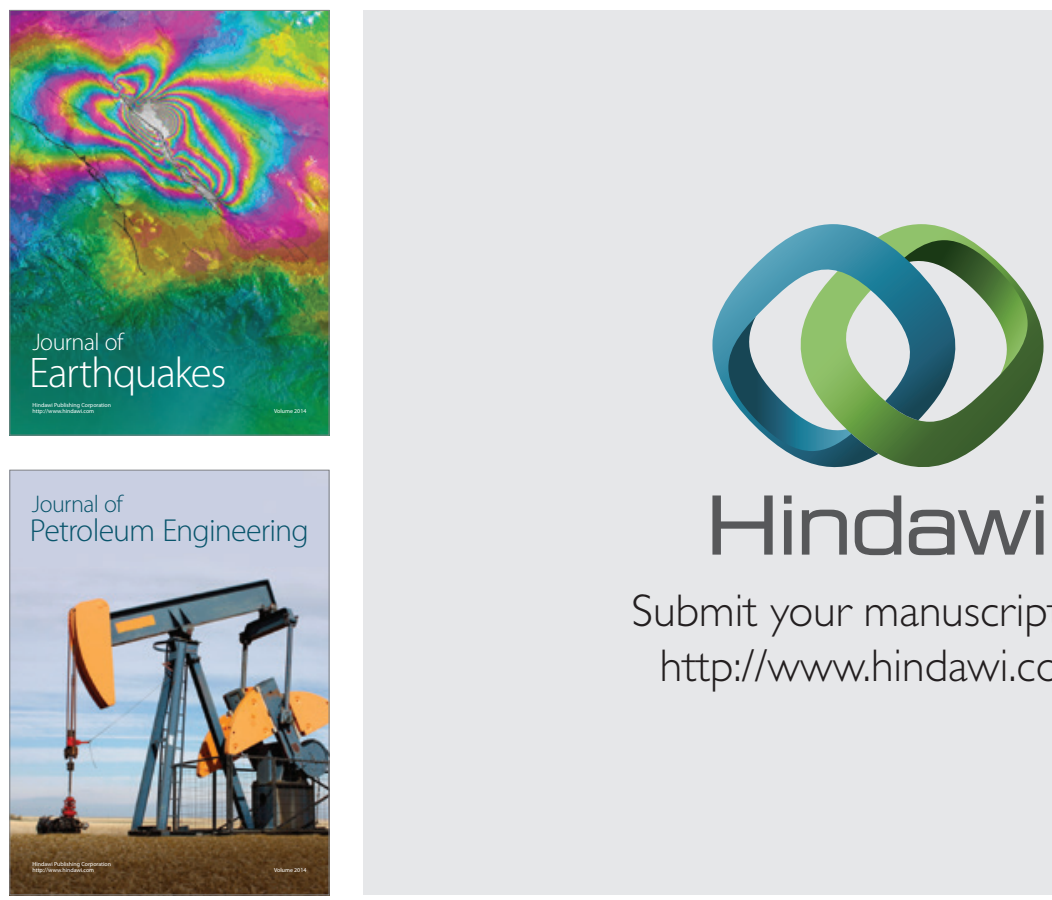

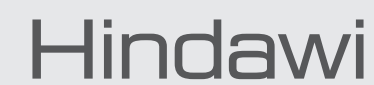

Submit your manuscripts at

http://www.hindawi.com
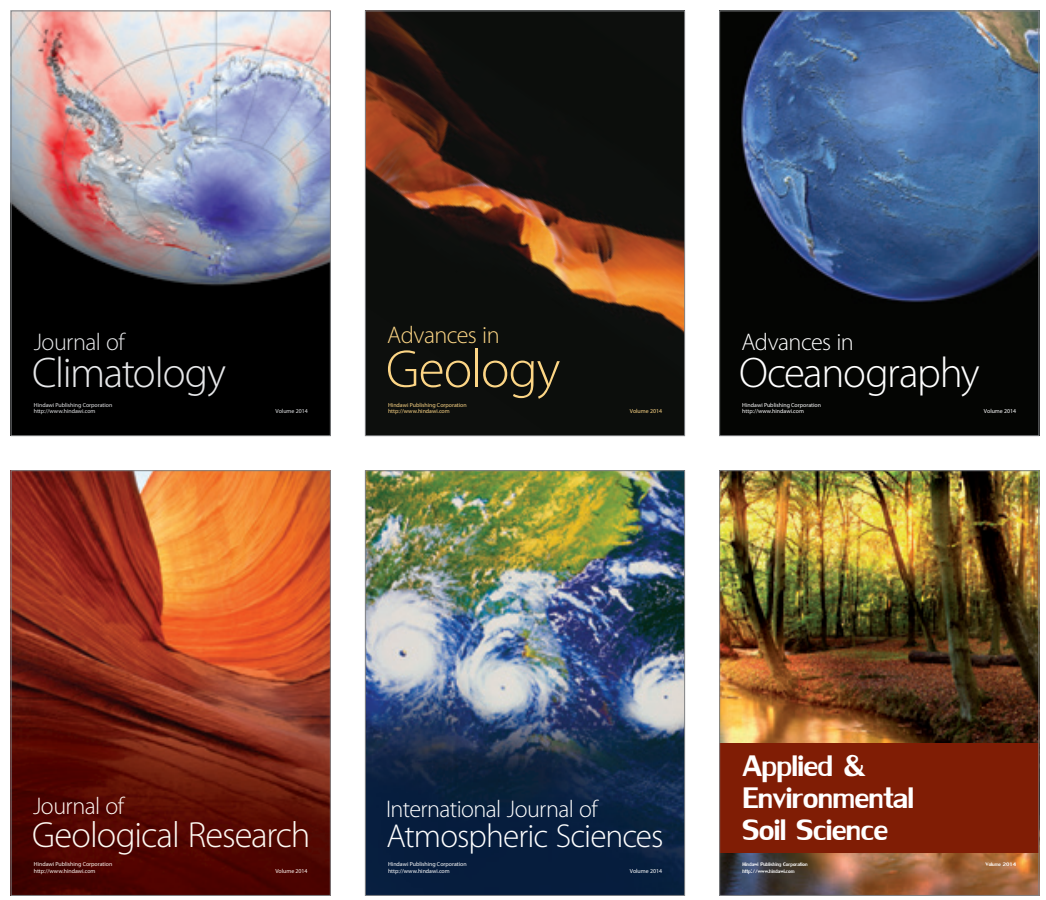
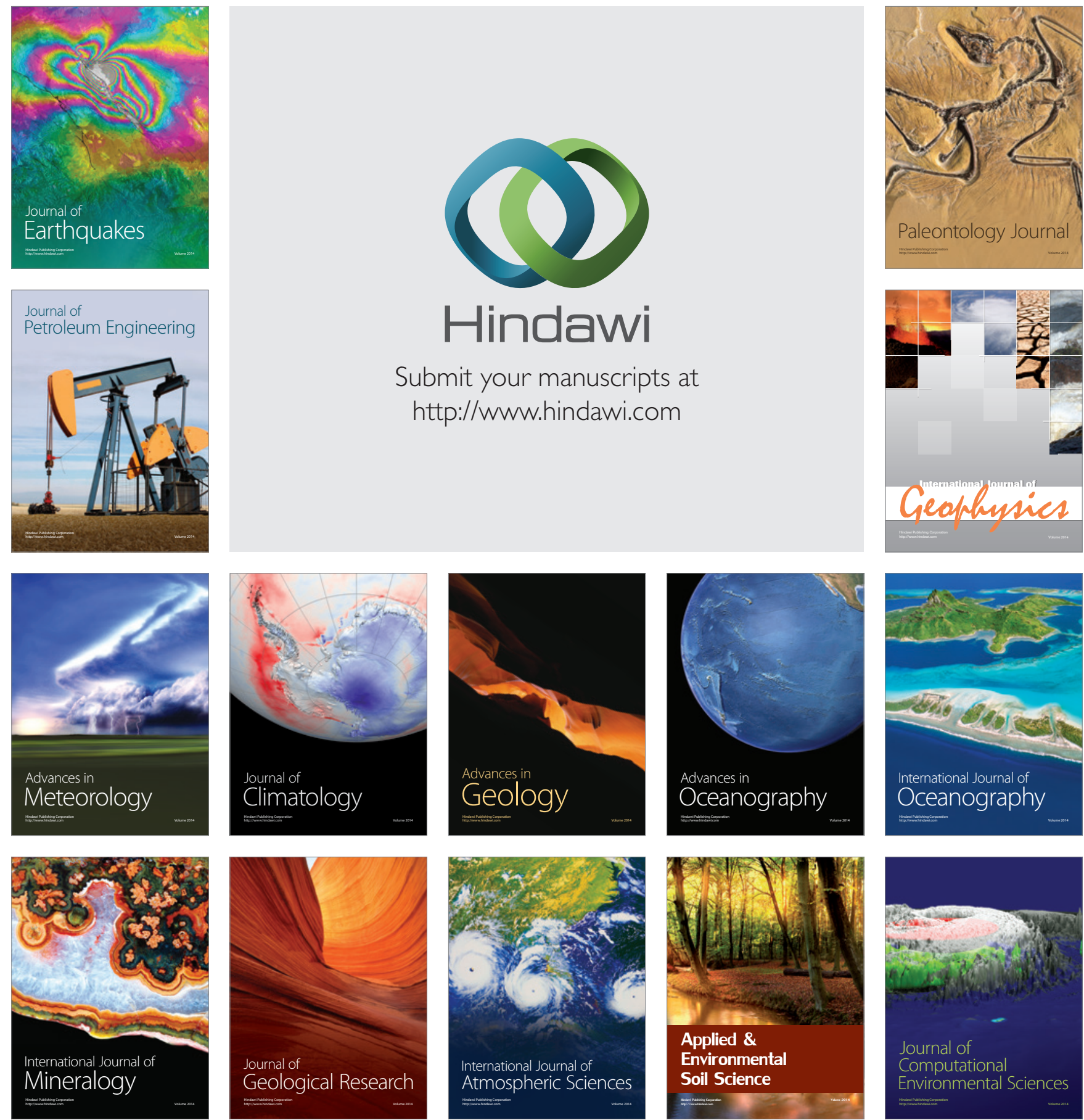